Review

\title{
Protection Coordination of Properly Sized and Placed Distributed Generations-Methods, Applications and Future Scope
}

\author{
Sunny Katyara 1,*, Lukasz Staszewski ${ }^{2}$, Zbigniew Leonowicz ${ }^{2, *}$ \\ 1 Sukkur IBA University, Pakistan, sunny.katyara@iba-suk.edu.pk \\ 2 Faculty of Electrical Engineering, Wroclaw University of Science and technology, Poland; \\ lukasz.staszewski@pwr.edu.pl,zbigniew.leonowicz@pwr.edu.pl \\ * Correspondence: sunny.katyara@iba-suk.edu.pk; zbigniew.leonowicz@pwr.edu.pl, Tel.: +48-71-320-2626
}

\begin{abstract}
- the radial distribution networks are designed for unidirectional power flows and are passive in nature. However, with the penetration of Distributed Generation (DG), the power flow becomes bidirectional and the network becomes active. The integration of DGs into distribution network creates many issues with: system stability, protection coordination, power quality, islanding, proper placement and sizing etc. Among these issues, the two most significant are optimal sizing and placement of DGs and their protection coordination in utility network. The proper coordination of relays with high penetration of DGs placed at optimal location increases the availability and reliability of the network during abnormal operating conditions.
\end{abstract}

This research addresses most of the available methods for efficient sizing and placement of DGs in distribution system (numerical, analytical and heuristic) as well as the developed protection coordination techniques for utility networks in the presence of DGs (Artificial Intelligence (AI), adaptive and non-adaptive, multi-agent, hybrid). This paper indicates the possible research gaps and highlights the applications possibilities and methods' limitations in the area of DGs.

Index Terms - Distributed Generation; protection coordination; optimal DG location; optimal DG sizing

\section{Introduction}

Distributed generation (DG) has gained enormous popularity due to its modularity, ease of deployment, operation and control. The term DG is given to the production of electricity near the load center. The decentralized nature of distributed generation makes the basis for micro-grids, where the concept of centralized generation and control does not exist anymore and leads to the smart grid solutions [1]. DG technology mostly involves Renewable Energy Sources (RES) and cogeneration. The integration of DGs into distribution network may pose both positive and negative impact depending upon the characteristics of distribution network and the DG itself. The positive impacts of DG installation are: power loss reduction, voltage profile and reliability improvement, power quality enhancement, no need of new transmission lines installation, and postponement of substation capacity upgrade [2]. Moreover, the DG does not contribute to the greenhouse gases providing clean and efficient energy. The negative effects of DG application are: fault current level increase, discoordination of protection schemes, islanding, bidirectional power flows, and transient instabilities [3].

The optimal size and location of incoming distributed generation are preliminary factors to maximize the system support benefits. The size and location of DG can be decided on the basis of enhancement of one or more distribution network parameters in a way to improve the energy efficiency and reduction of negative impacts of the installation [4]. Optimal size and location of DG improves also the performance 
and operation of whole network. The additional power delivered by DG significantly affects the bus voltage, load characteristics and reliability of the system [5]. Therefore, at the planning stage of distribution system, one of the most crucial and difficult task is to estimate the capacity and location of futures in the network. Different techniques are used for such estimations (e.g.: numerical, analytical, and heuristic) and all of them were analyzed in terms of the efficient placement and sizing of DGs.

Since the main function of protection schemes in distribution networks is to immediately isolate the faulty part of the system from the healthy one for the fault occurrence. Thus, mostly overcurrent relays are used in such networks as primary and backup protection. The coordination of overcurrent relays is arranged in such a way that if the fault is not cleared by the primary relay then it should be backed by another relay.

With the introduction of DGs, the existing schemes for distribution network protection become inactive. The intensity of this discoordination depends upon the type, size and location of installed DG [6]. Since the radial utility networks are designed for unidirectional current flows so are protection schemes. With the DG installation, the distribution network forms a closed loop and current flows in both directions thus the existing relays do not protect the system effectively during the faults. One of the possibilities of solving this problem is use of directional overcurrent relays that are able to discriminate between upstream and downstream current flows [7]. Another option is to reset the Time Multiplier Settings (TMS) and Plug Multiplier Settings (PMS) of relays after integration of each DG [8]. However, Distribution System Operators (DSOs) are not in favor of changing the relays settings or network configuration manually. Many adaptive, non-adaptive, multi-agent, Artificial Intelligence (AI), hybrid, etc. techniques are evolved for proper and efficient coordination of relays.

This research addresses most of the available methods for efficient sizing and placement of DGs in distribution system (numerical, analytical, and heuristic) as well as the developed protection coordination techniques for utility networks in the presence of DGs (Artificial Intelligence (AI), adaptive and non-adaptive, multi-agent, hybrid). This paper indicates the possible research gaps and highlights the applications possibilities and methods' limitations in the area of DGs.

Methods for Location and Size of DG

The methods for location and sizing of DG are divided roughly into three categories: numerical, Analytical, and Heuristic.

\section{A. Objectives}

The objectives of different methods of Optimal Sizing and Location of DG (OSLDG) into distribution network include [9]:

1) minimizing the power losses,

2) enhancing the voltage profile of network,

3) increasing the reliability of network,

4) improving the loading capacity of network on the basis of voltage constraints,

5) maximizing the economy of utility operator,

6) maximizing the MVA capacity requirements of network.

\section{B. Constraints}

The single and multi-objective function of different methods of OSLDG involves many optimization variables with the following possible constraints [10]:

1) power balance in the network,

2) fault level and thermal limits,

3) voltage limits,

4) reliability and economic limits,

5) allowable number of DGs in the network,

6) power factor limits. 


\section{DG technologies}

The devices used for distributed generation include directly connected to the system rotating machines (induction or synchronous), as well as static and rotating devices, which are coupled to the network through electronic converters. Different DG technologies have various influences on the operation, control and stability of a system e.g.: the inverter based DGs inject harmonics into the system while the rotating machines create issues for the protection coordination in the distribution network [11]. Most of the effects of distributed generation technologies depend solely upon the size and location of DG installation in the utility network.

\section{Numerical methods}

Numerical methods are based on mathematical programming and analysis and they are listed below. The common and general idea of operation is presented with use of the flow diagram in Fig. 1. The summary of presented methods is gathered in Table. I.

1) Gradient search - this method, proposed in [12] and [13], is used to find the proper size of DGs in mesh networks while considering and ignoring the short circuit capacity limits of the network.

2) Linear programming - this method, evolved in [14] and [15], is used to find the optimal location of DG in the distribution network with maximum allowable penetration and energy harvesting from DGs.

3) Sequential Quadratic Programming (SQP) - itis a second order differential technique, presented in [16], [17], and [18], is used to find the optimal location and size of multiple DGs in distribution network, without considering the short circuit capacity limits of network. The main objective is to reduce overall power losses in the network.

4) Exhaustive search - a multi-object technique, used in [19], [20], [21], and [22], used for finding proper location and size of DGs with main focus on reliability improvement and loss minimization at fixed and variable load models. The time-varying behavior of renewable sources and loads were considered in [23].

5) Ordinal optimization - this method, suggested in [24], is used to find the optimal location and size of DGs in the distribution network making compromise between the power losses minimization and maximizing the allowable penetration of DGs.

6) Dynamic programming-this method's used to find the optimal size and location of multiple DGs, main objective is to maximize the economy of utility operator at different loading conditions [25].

7) Nonlinear programming-this technique converts probabilistic model with all network constraints into deterministic model using optimal load flow [26], [27], [28]. Mixed-Integer Non-Linear Programming (MINLP) isspecially used for proper placement of multiple wind units simultaneously and can also be used for other types of DG but only for single units [29]. An interior point technique is used to find the maximum capacity of utility network for DG integration through optimal load flow analysis [30]. MINLP is used to determine the optimal location and size of inverter based DGs with main objective of enhancing the voltage stability margin of the network [31]. MINLP is used in [32], [33] to determine the optimal location and size of DGs in distribution network while considering the variations in the market based energy prices. MINLP implemented in [34] is used during distribution system planning for investigation of the proper location and size of future DGs.

8) Load model- this method is used to locate and size the DGs in a distribution network having constant and variable power flows. Load models have great significance in stability studies. Three different voltage dependent load models i.e.: residential, commercial and industrial are considered for investigation [35].

9) Protection coordination index - the integration of DGs greatly affects the protection coordination of distribution network. Protection coordination index (PCI) is an indicator which represents the change of time coordination between the protection devices with change of penetration level of DGs into distribution network [36].

10) Contingency analysis - this technique is used to analyze the impact of size and location of DG on distribution system after fault inception. Voltage profile of DG is investigated before and after the occurrence of fault to calculate voltage regulation of system. Based on loading conditions and network configuration the appropriate size and location of DGs can be decided [37], [38]. 


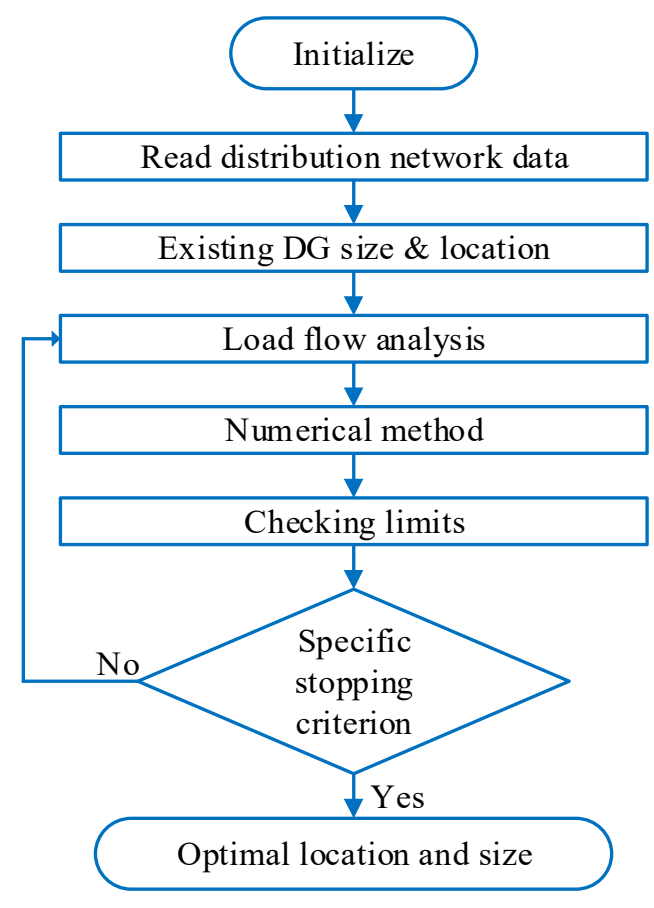

Fig.1. General flow chart for numerical methods.

Table 1. Summary of Numerical Methods for Placement and Sizing of DGs.

\begin{tabular}{|c|c|c|c|c|c|}
\hline Technique & Main features & Merits & Demerits & $\begin{array}{c}\text { Network } \\
\text { configuration }\end{array}$ & Objectives \\
\hline $\begin{array}{c}\text { Gradient method } \\
{[12][13]}\end{array}$ & $\begin{array}{l}\text { Computing hessian } \\
\text { of second order } \\
\text { network matrix with } \\
\text { and without faulty } \\
\text { conditions }\end{array}$ & $\begin{array}{l}\text { Fast convergence, } \\
\text { easy implementation }\end{array}$ & $\begin{array}{c}\text { Diverges at } \\
\text { positive or small } \\
\text { penetrations of } \\
\text { DGs }\end{array}$ & $\begin{array}{c}\text { 6-bus meshed } \\
\text { network }\end{array}$ & $\begin{array}{c}\text { To reduce of active and } \\
\text { reactive losses and } \\
\text { loading on the buses }\end{array}$ \\
\hline $\begin{array}{c}\text { Linear } \\
\text { programming } \\
{[14],[15]}\end{array}$ & $\begin{array}{l}\text { Limiting voltage, } \\
\text { thermal capacity, } \\
\text { fault level and } \\
\text { ratings of generator } \\
\text { as linear constraints }\end{array}$ & $\begin{array}{l}\text { Can be applied to any } \\
\text { type of radial network }\end{array}$ & $\begin{array}{c}\text { Does not produce } \\
\text { effective results } \\
\text { with changing } \\
\text { network } \\
\text { dynamics }\end{array}$ & $\begin{array}{l}\text { 5-bus radial } \\
\text { distribution } \\
\text { network }\end{array}$ & $\begin{array}{c}\text { To maximize the } \\
\text { generation capacity of } \\
\text { DG }\end{array}$ \\
\hline $\begin{array}{c}\text { Fast sequential } \\
\text { quadratic } \\
\text { programming } \\
{[17]}\end{array}$ & $\begin{array}{c}\text { Formulating } \\
\text { non-linear } \\
\text { optimization } \\
\text { function of network } \\
\text { with nonlinear } \\
\text { inequality and } \\
\text { equality limits }\end{array}$ & $\begin{array}{l}\text { Applicable to } \\
\text { multiple DGs with } \\
\text { unspecified power } \\
\text { factors \& takes least } \\
\text { computation tim }\end{array}$ & $\begin{array}{l}\text { Not suitable for } \\
\text { network with } \\
\text { changing } \\
\text { dynamics }\end{array}$ & $\begin{array}{l}\text { 69-bus radial } \\
\text { distribution } \\
\text { network }\end{array}$ & $\begin{array}{l}\text { To minimize the } \\
\text { system power losses }\end{array}$ \\
\hline $\begin{array}{l}\text { Exhaustive } \\
\text { search [19] }\end{array}$ & $\begin{array}{l}\text { Determining load } \\
\text { conditions of } \\
\text { network at different }\end{array}$ & $\begin{array}{c}\text { Simple, cost effective } \\
\text { solution }\end{array}$ & $\begin{array}{l}\text { Not suitable for } \\
\text { multiple DGs }\end{array}$ & $\begin{array}{l}3 \text { radial } \\
\text { circuits }\end{array}$ & $\begin{array}{l}\text { To reduce of power } \\
\text { losses and } \\
\text { improvement of }\end{array}$ \\
\hline
\end{tabular}


DG sizes

Making tradeoff

between total energy

\section{Ordinal}

optimization

[24]

\section{Dynamic \\ programming}

[25]

\section{Nonlinear \\ programming}

[26]

Load model

[35]

Protection

coordination

index

[36]

Contingency

analysis

[37] losses and

generating capacity

of network on the

basis of nonlinear

power flow

calculations

Maximizing the

economy of utility

network while

considering variable

load models

Making compromise

between the energy

losses and

generation capacity

with optimal power

flow

Maintaining the

voltage at the buses

under prescribed

limits with variable

active and reactive

$$
\text { power }
$$

Trying to keep the

PCI on the lowest

level possible as the

changes in

penetration of DGs

affects the

coordination timing

between the relays

Estimating the

network voltage

profile before and

after faults with and
Less computational

time

Enhances voltage profile of system,

reduces computation

time

Applies to wind
based DGs due to
their time varying
nature

Real time data of market prices is

necessary as one

of the variables

\section{Efficiency of}

model is very low

Suitable for complex

networks with

changing dynamics

Used for both

synchronous and

static DGs. Helps

utility operator to

determine the

maximum amount

DGs that can be

added to system

Suitable for network

with varying load

conditions and

unbalanced power when applied to

ring-main

distribution

networks

Not suitable for

networks with

changing

parameters

Unreliable results on upstream

buses without DGs network profile of network \\ system reliability \\ 8-bus radial network \\ 61-bus \\ distribution network \\ 38-bus radial distribution network \\ To minimize total energy losses and maximizing generating capacity To minimize power
losses and improve reliability of network energy losses and maximizing generating capacity \\ 14-bus and reactive power losses, 30-bus IEEE improve voltage network profile and restrict fault level and thermal limits \\ -bus IEEE To enhance voltage}




\section{E. Analytical methods}

These methods are the combination of different techniques used to evaluate the characteristics of network qualitatively and quantitatively. Listed below techniques are based on mathematical expressions. The general flow diagram for such techniques is shown in Fig.2 and the summary for these methods is given in Table II.

1) $2 / 3$ rule - applied for the distribution networks with uniformly distributed loads. The rule states, the incoming DG should have $2 / 3^{\text {rd }}$ capacity of existing distribution network and should be installed at $2 / 3^{\text {rd }}$ length of a line [39]. Non-effective for non-uniformly distributed loads.

2) Kalman's filter algorithm - used for finding the optimal size of multiple DGs in combination with Optimal Power Flow (OPF) technique [40]. OPF is used for finding the proper location of all the DGs in the distribution network, then Kalman's filter is applied to find their suitable ratings.

3) Loss sensitivity factor technique - used for calculation of the equivalent current injections of all DGs on the basis of load flow analysis and for determination of their proper size and location. It employs matrix algebra [41].

4) Exhaustive load flow technique - based on the power factors of DGs being connected to the distribution network. The computational process is done twice: firstly for losses calculation and secondly for losses reduction [42].

5) Improved analytical approach - based on the Improved Analytical (IA) expression and used for finding the optimal location and size of multiple DGs. The IA expression is formed by taking into account the active and reactive powers, and power factors of all the DGs [43].

6) Exact loss formula - analytical method used for development of an expression incorporating the exact relation between the network losses with proper placement and sizing of DGs. Nonlinear curves are obtained between optimal place and size of DG and the network losses [44].

7) Analytical approach with micro-generation - technique proposed in [45], based on the loss contribution of micro-generators in LV networks at different load conditions. Method used for determination of size, location and number of DGs to be installed in the network based on quantity of avoided losses.

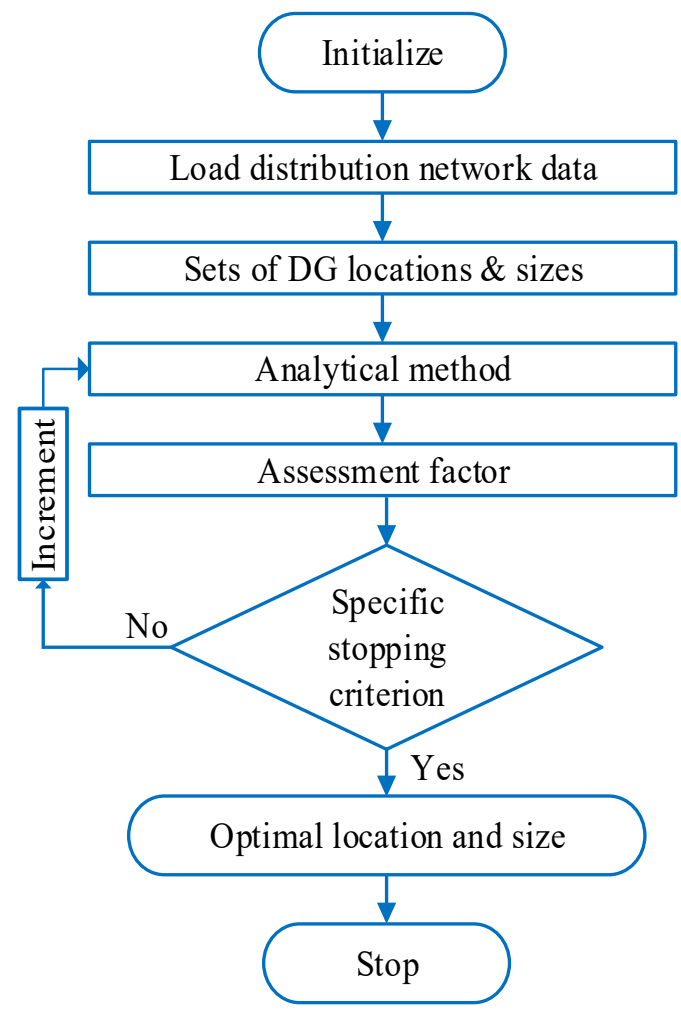

Fig.2. General flow chart for analytical methods. 
TABLE II

Summary of ANALytical Methods for Placement AND Sizing of DGs

Technique

Kalman's filter

algorithm

[40]

[39]

Kalman's filter
algorithm
[40]

Loss sensitivity

factor technique

[41]

Exhaustive load

flow technique

[42]

Exact loss formula

[44]

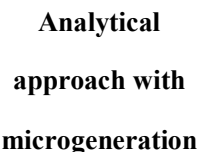

[45]

Improved

analytical

approach

[43]

Main features
Installing DG of

2/3rating of total

capacity of network at

$$
\text { 2/3 length }
$$

Considering total

power loss in steady

state and sorting out

the best samples from

entire sets of DG's size

$$
\text { and location }
$$

Estimating the

equivalent current

injections of DGs

Executing load flow

twice for loss

\section{calculation and}

reduction and for

$$
\text { different }
$$

configurations and

power factors of DGs

Maintaining balance of

$\begin{array}{ccc} & \text { of system } \\ & \begin{array}{c}\text { Generating search } \\ \text { tables for different }\end{array} \\ \text { Exact loss formula } & \text { combinations of DGs } \\ \text { [44] } & \text { and to analyze them by } \\ \text { exhaustive load flow } & \text { Determining the } \\ \text { Analytical } & \text { amount of avoided } \\ \text { approach with } & \text { losses on the basis of } \\ \text { microgeneration } & \text { type of load } \\ \text { [45] } & \text { distribution and }\end{array}$

Merits

Simple, easy to

implement

Least

computational

times

Easy, fast with

desired

accuracy

Effective with

variable load

models

Can be used for

any number of

DGs and has

least

computational

times

\section{Can be applied Not suitable for} to complex

networks

Highly

recommended

for practical

Cannot be applied to

variable load models

used

\section{Protection \\ coordination schemes becomes complex}

varying characteristics

of network

\section{Network}

\section{configuration}

Objectives

Not suitable for

networks with

non-uniform load

33-bus IEEE network

distribution

Pre-processing data of

system losses and DG

30-bus IEEE network

rating are required

Cannot be applied to

$$
\text { multiple DGs }
$$

Restricted to local

16, 33 and 69-bus

radial networks

To minimize total power

losses
To minimize power

losses

12, 34 and 69-bus

radial network

To minimize total power

losses
30, 33 and 69-bus radial networks

To minimize total power

losses

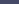


penetration of

micro-generation

\section{F. Heuristic methods}

The heuristic methods are one of the optimization techniques, used to select the best possible solution among the set of different possible results. The general flow chart for such methods is shown in Fig. 3 and the summary of these methods is given in Table III.

1) Genetic algorithm - a biology-inspired algorithm which uses chromosomes built from genes to find out the optimal location and size of DGs. Using limits of crossover and mutation operator, the best possible solution is obtained [46]. GA used in [47] solves the problem of optimal location and size of DGs based on reliability constraints. GA is employed to solve the optimal location and size of DGs based on different load models [48], [49]. In [50] GA is used to maximize the profit of utility operator by deciding proper size and place of DGs in distribution network. Considering power quality issues, GA in combination with decision variable theory is used to find the optimal location and size of DGs [51]. GA in combination with fuzzy theory is used to find proper location and size of DGs with main focus to minimize the power losses [52], [53], [54], and [55].

A technique with weights considering economy and merits of DGs is solved by GA for their optimal location and size [56].For maximizing the profits of consumers and suppliers GA is applied to find the proper size and location of DGs in distribution network [57]

2) Particle swarm optimization -method based on natural phenomenon, inspired by social characteristics of bird flocking. The method has many similarities with genetic algorithm [58]. Based on the real and reactive powers injections of DGs, the PSO method is applied to find the proper location of DGs in distribution network [59], whereas based on the power factors of DGs, the PSO algorithm is applied to find the optimal location and size of DGs in distribution network at different load models [60]. Another possibility of considering the harmonic and protection coordination limit, the PSO algorithm is applied for finding the best location and size of rotating and static DGs [61].

3) Ant colony optimization - method inspired by the behavior of ants which find shortest path to find food [62]. ACO algorithm suggested in [63], is used to find the optimal location and size of DGs while reducing network's active power losses.

4) Artificial bee colony- technique inspired by the behavior of honey bees called swarms that have intelligent foraging characteristics [64]. ABC algorithm was used in [65] for finding the optimal location and size of DGs on the basis of their power factors and active power losses of network.

5) Differential evolution - an evolutionary algorithm which optimizes the results in steps on the basis of defined constraints. It may also optimize the objective functions that are not continuous in nature [66]. Based on the voltage sensitivity of buses, the DE is used to compute the best location and size of incoming DGs [67].

6) Harmony search - a musical based heuristic method inspired by the characteristics of music searching for the perfect state of harmony [68]. The problem evolved by loss sensitivity factor technique for determining the proper location of DGs is further solved with use of HS algorithm for finding their optimal sizes [69].

7) Tabu search - mathematical optimization technique used to find the best possible solution on the basis of user defined rules or search tables [70]. TS algorithm, used in [71], and [72], for uniformly distributed loads finds the optimal location and size of DGs with defined constraints of loss minimization and voltage profile enhancement.

8) Big bang big crunch algorithm- is a method inspired from the two theories of universies, big bang and big crunch. It produces random set of points in the big bang plane and distributes them to the big cruch plane through minimum cost function. BB-BC used in [73], optimally sizes and places the multiples DGs on the basis of performace indices of system.

9) Practical heuristic algorithms - methods used for learning, solving and discovering solutions without the optimal solution guarantee. However, these techniques are suitable for instant results [74]. A heuristic approach was used in [75] for placing and sizing the DGs on the basis of market based economy and benefits provided to network at peak demands. The heuristic method suggested in [76] for placing only one DG on the basis of its power loss contribution to the network. A heuristic method used in [77] for placing the DG in the network by reducing the 
cost of network reliability. A heuristic method evolved in [78] was used for placing and sizing the DGs in steps by optimizing the variables of fitness function for maximizing the benefits from DGs introduction into the network.

10) Hybrid optimization algorithms - many optimization algorithms can be combined together (e.g.: PSO, GA, DE, $\mathrm{ABC}, \mathrm{ACO}$, etc.), to obtain the best possible solutions utilizing the benefits collectively [79]. A hybrid ACO and $\mathrm{ABC}$ was used in [80] to find the proper location and size of DGs by maximizing the economy and voltage stability of network and reducing power losses and emission rates of associated energy resources. A hybrid tabu search and genetic algorithm is suggested in [81] with major focus on maximizing the voltage profile and decreasing the power losses of investigated network was used for finding the optimal location and size of DGs. A hybrid GA and PSO algorithm, was used in [82] for finding the optimal location and size of multiple DGs.

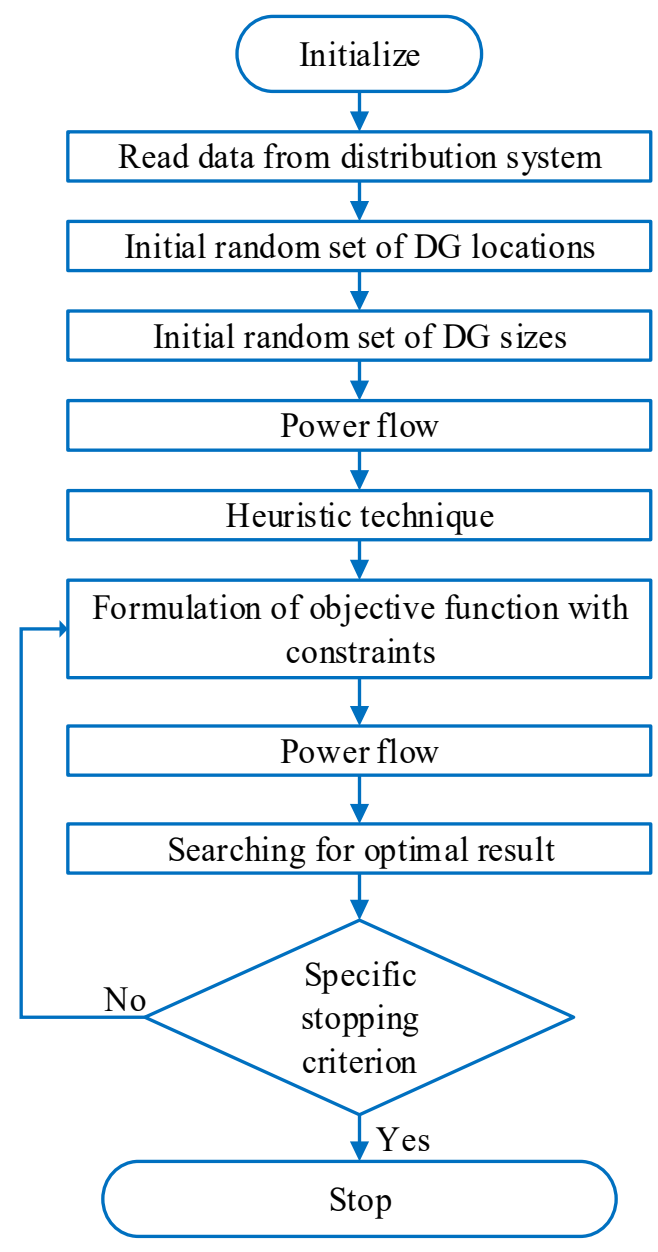

Fig.3. General flowchart for heuristic methods.

TABLE III

Summary of Heuristic Methods FOR Placement AND SizING OF DGs

$$
\begin{array}{cc}
\text { Technique } & \text { Main features } \\
\text { Genetic algorithm } & \text { Determining the cross over } \\
\text { [46], [47] } & \text { fitness function for all } \\
& \text { possible sets }
\end{array}
$$

Particle swarm
Determining the velocity of
Merits

Demerits

Robust and

results are not

restricted to local

minimum

solution

Small

needed
Network

configuration

The convergence

time is high when

precise results are

14-bus IEEE

network

To minimize power losses

and to enhance voltage

profile of network

38-bus radial

\section{Objectives}

Protection

To minimize active and 


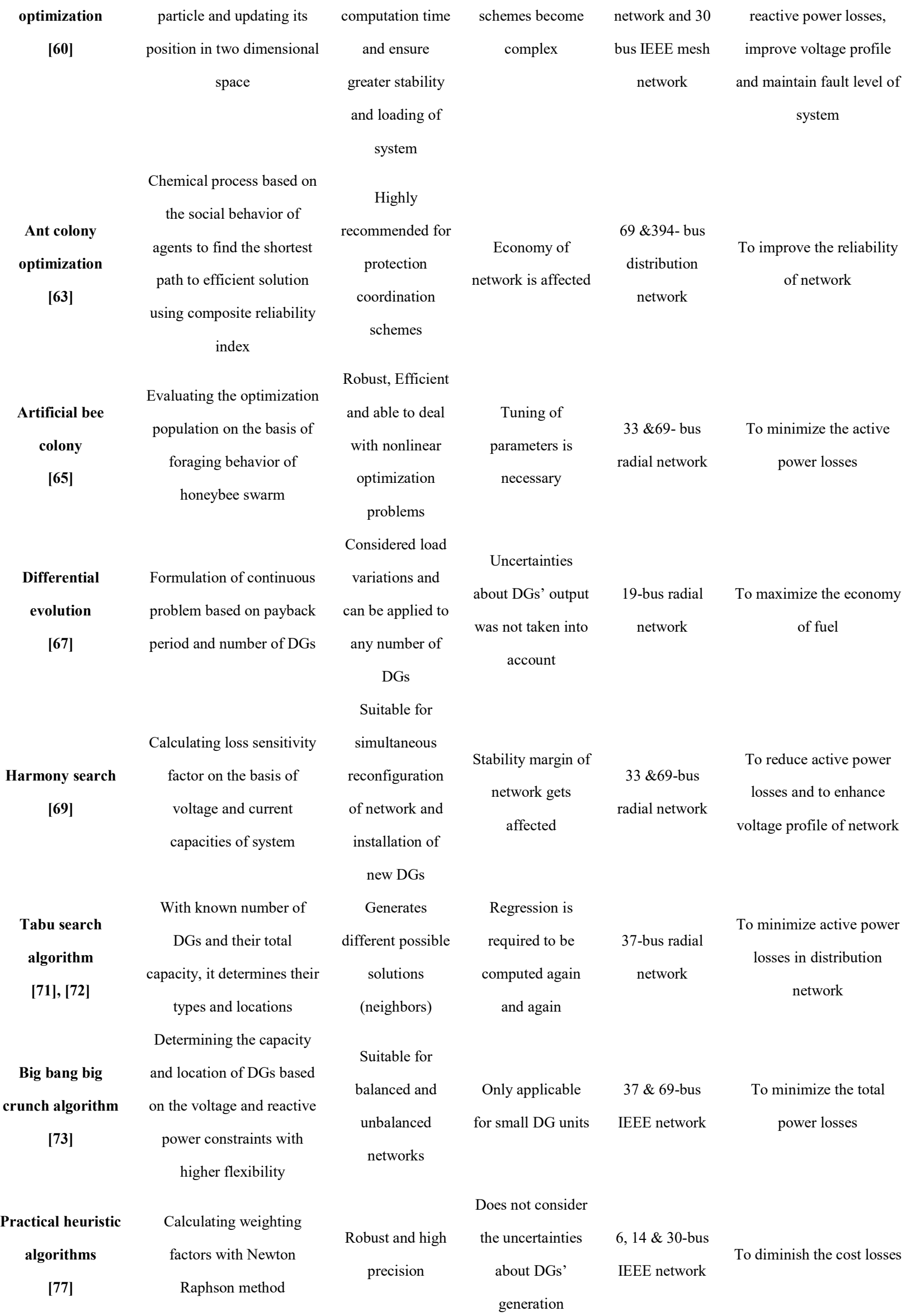




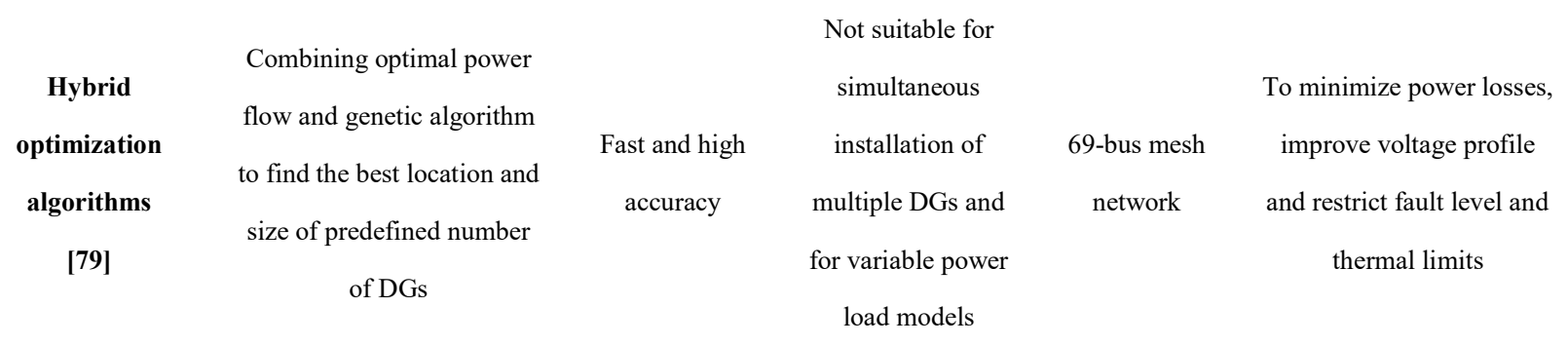

\section{Protection Coordination}

Since, the integration of Distributed Generation into distribution network cause the bi-directional energy flow, the current levels during the fault inception increase in comparison to the ones without the DGs contribution. Therefore, the already existing, traditional protection schemes may fail to operate efficiently and may cause nuisance and false trippings [83]. Hence, as the efficient coordination of protection devices is necessary for correct operation of distribution network, the renewed relay settings are required after DG installation. The protection coordination issue limited to the downstream network is called a small scale problem while the extension to the upstream network is called a large scale problem [84].

For each incoming DG the settings of primary and back-up relays are required to be changed accordingly. Moreover, the directional element is integrated with overcurrent relays for distinguishing upstream and downstream faults after integration of DGs when power flow becomes bi-directional. Determination of the new relays settings is not an easy task, therefore many different adaptive and non-adaptive algorithms and techniques are used to do so. The new designed protection coordination techniques must be efficient for information monitoring, control and communication and are known to be global protection and control schemes [85], and [86].

The impact of DG integration on the protection coordination highly depends upon its type, location, and size. Moreover, the characteristics of DG and distribution network are also important factors to be considered while computing new settings for protection devices. It is worth mentioning, that the synchronous DGs contribute to large fault currents, irrespectively of the network configuration, while the inverter based DGs contribute to small fault currents [87].

G. Study objectives

The prime objectives of the studies over the protection coordination are:

1) maintaining the standard Coordination Time Interval (CTI),

2) updating the Time Multiplier Settings (TMS) and Plug Multiplier Settings (PMS) of relays,

3) ensuring selectivity, speed, reliability, cost, and simplicity of protection devices.

\section{H. Popular protection devices for distribution network}

The most popular devices used for protection of low voltage distribution networks are as follows:

1) fuses,

2) overcurrent relays:
a) directional,
b) inverse time,
c) definite time,
d) instantaneous. 


\section{Methods of protection coordination}

Most of researches, in the area of protection coordination techniques, have been done for DGs tied to distribution network. Comprehensive summary of all the important methods discussed in different research papers are presented below and their summary is gathered in TableIV.

Expert system based protection coordination - expert system is a software inspired by the human behavior of solving issues or making rational decisions. Expert systems are used where the traditional data processing is not feasible. Operating on their knowledge database and expertise the expert systems, as a result, also give the reasons on the solution choice [88], and [89]. Expert systems are used in industrial networks for relay coordination after DG integration. Multiple relay settings were evolved for $22 \mathrm{kV}$ distribution network using expert systems [90], on the basis of load flow, and fault analysis. The general scheme diagram for expert system based protection coordination is shown in Fig.4 [90].

The utilization of expert systems for coordination of the protection devices (i.e.: relays, fuses and reclosers) in a $33 \mathrm{kV}$ radial system for small scale DGs is suggested in [91]. Protection Device Coordination Expert System (PDCES) software is developed in [92] to help the utility operator evaluate the protection coordination issues. PDCES assesses the causes of misscoordination, proposes solutions, and ranks the remedies, so that an appropriate action can be taken in accordance to the network characteristics. The potential usage of expert system in protection coordination studies is proposed in [93],

and [94].

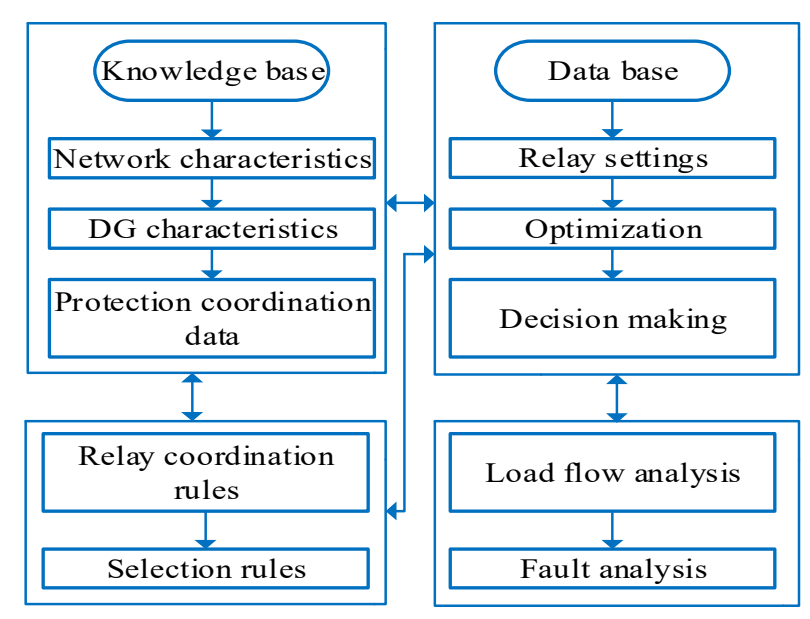

Fig.4. Expert System based protection coordination scheme.

Adaptive protection coordination - an emerging technique in power systems with low DGs penetration. It has ability to automatically process the data when conditions of the network changes with integration of DG. The defined rules and algorithms take the necessary actions accordingly, to achieve the high level of protection coordination in all the abnormal scenarios [95]. The adaptive technique used in [96], checks the relay settings after connection of every new DG on the basis of short circuit currents flowing through the protective devices. Adaptive scheme used in [97], evolves the coordination between protective devices on the basis of coordination time interval margin between their curves. An adaptive scheme suggested in [98] maintains coordination between the fuses in distribution network but all the DGs get disconnected at the instant of fault.

Fault current limiter (FCL) based scheme - integration of DGs into distribution system affects its overcurrent protection schemes and increase the level of fault current closer to the rating of protective devices [99]. The general scheme of FCL based protection coordination is shown in Fig. 5 below. 


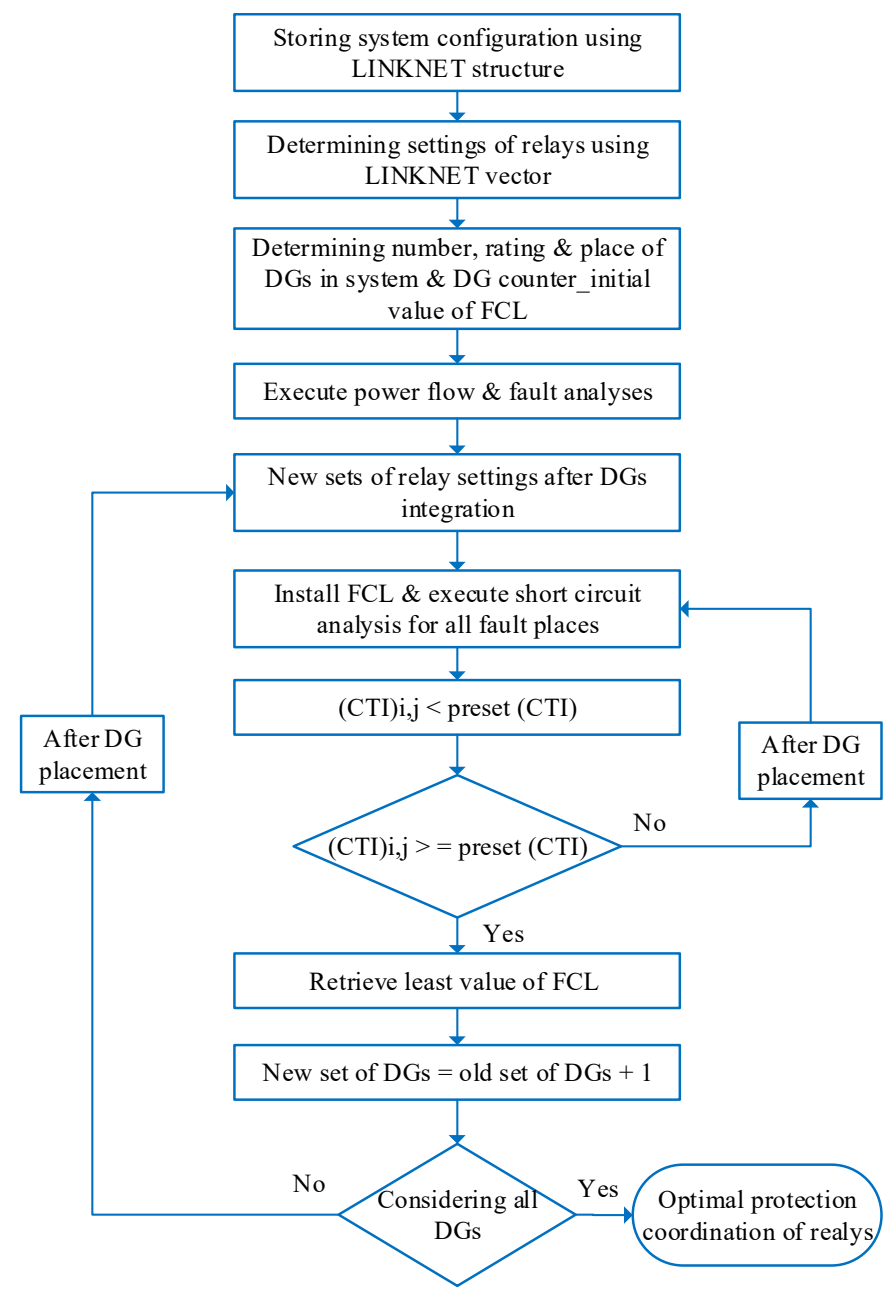

Fig.5. FCL based protection coordination.

One way to overcome the issue of misscoordination between protection devices after DG integration might be a replacement of the existing scheme for a new one with higher rating, but this would be a costly option. Another way is to limit the value of fault current to the acceptable level so that the existing schemes may operate effectively [100]. The fault current limiters are connected in series with distribution lines to limit the amount of fault current contributions from the DGs. However, fault limiters cause small amount of loading and contribute to the power losses during normal conditions [101]. The LINKNET is type of data structure used to determine the set of random variables.

Directional overcurrent protection coordination - the directional element is added to the conventional overcurrent relays to deal with the bidirectional power flows caused by integration of DGs. This ideais used in [102], [103], and [104] to isolate internal and external faults in the microgrid. The scheme of operation is based on directional overcurrent relays with additional communication and is relatively expensive. The directional protection scheme with master-slave concept is suggested in [105] to protect the micro-grid system against the external and internal faults. The proposed scheme has communication ability to detect the direction and location of fault. The directional protection scheme using microprocessor based relays proposed in [106] is used to protect the connected grid and also islanded DGs. This proposed scheme does not require communication link and is independent on the level of fault current values and the operation mode of DGs. The limitations of directional overcurrent protection have been identified in [107]. It is pointed out that the unintentional and frequent connection and disconnection of DGsaffects the network configuration and the settings of protection devices.

Time-inverse protection coordination - when the fault occurs in a radial utility network, the prime source of fault current is a supply side. There is a huge difference between the magnitudes of fault current and load currents so the overcurrent relays are able to distinguish between faulty and normal conditions. However, after the installation of 
DGs, the margin between the load current and fault current is small and thus the relays cannot efficiently discriminate between them [108]. A method based on voltage-current inverse characteristics is proposed in [109], [110], and [111] to discriminate between the faulty and normal conditions.

Selection of DG's location and size - the location and size of DG have significant importance in the protection coordination study. The optimal sizing and placement of DG would cause small disturbances in coordination schemes of distribution network. The general scheme of such a method is shown in Fig.6.

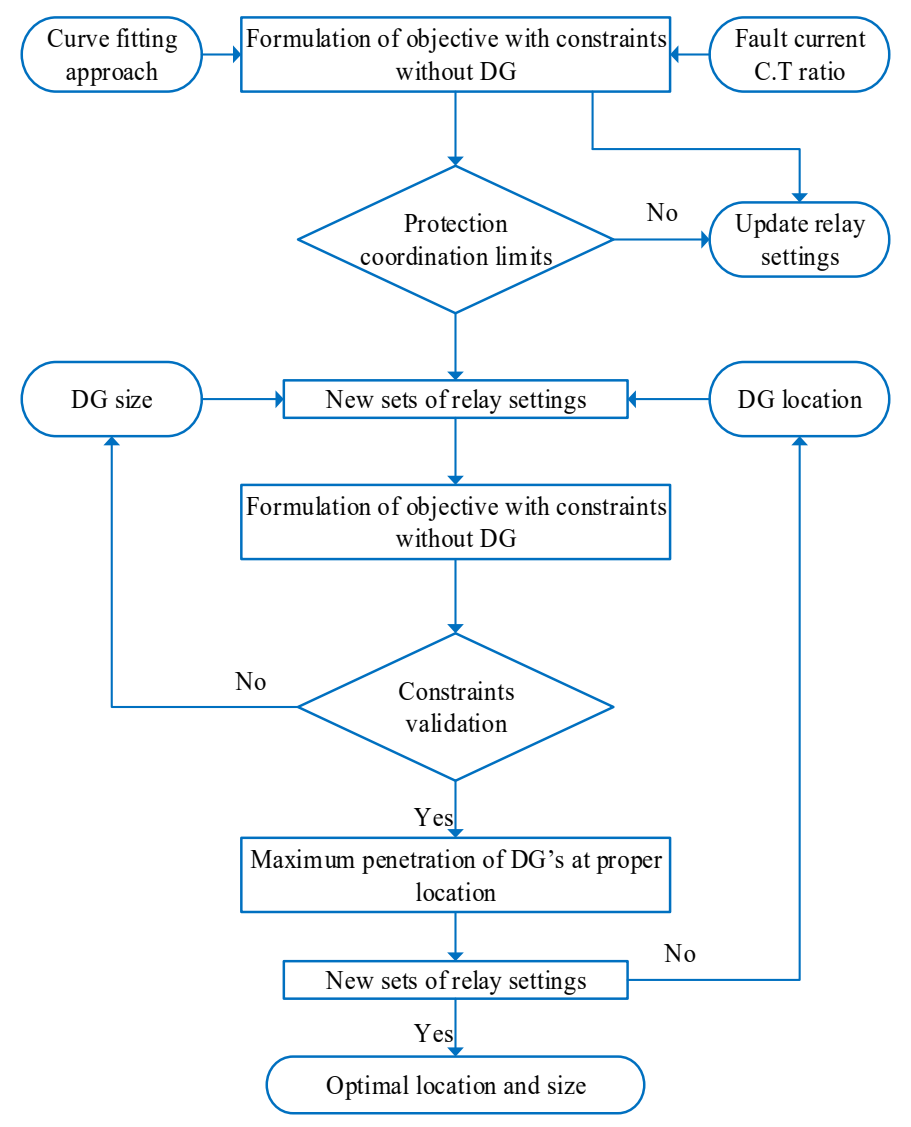

Fig.6. DG's location and sizing based relaying scheme.

The protection coordination scheme discussed in [112] evaluated the effect of size and location of DG on the overcurrent network protection based on fault current in upstream and downstream networks. In [113] the limitations for DGs' penetration are suggested to maintain coordination between conventional protection devices. The effect of size and location of DG on the coordination time interval (CTI) margin of inverse time overcurrent relays is analyzed in [114]. The sensitivity of relays in upstream and downstream network at different DG's location and size is also discussed.

Neuro-fuzzy based protection coordination - with the growing popularity of Artificial Intelligence in the power system applications the protection coordination methods are using fuzzy logic and neural network approaches [115]. Multi-Layer Perceptron Neural Network (MLPNN) based protection coordination scheme is being suggested in [116], and [117]. However, this method is not robust due to training and complex structure of neural networks. The protection coordination scheme based on fuzzy logic approach proposed in [118] minimizes the operational time of primary and backup relays and evolutionary algorithm is used to optimize them. In order to add the decision making ability the fuzzy logic is adapted. Three stage neural network based protection coordination scheme is suggested in 
[119]. The first stage determines the distance to the fault point and the second stage identifies the exact location of fault while the third stage is used to isolate the faulty part from the network.

Multi-agent protection coordination - a method gaining popularity in protection coordination studies. An agent is an intelligent system which performs the defined autonomous functions in order to achieve desired objectives. The task performed by agents exist in predefined environment and their infrastructure contains communication and interface links [120]. The general scheme of multi-agent protection coordination is shown in Fig.7 [121]. An efficient protection coordination scheme using multi-agents for distribution networks with DGs connected is proposed in [122], [123], and [124]. A multi-agent based protection coordination scheme proposed in [125] coordinates the overcurrent relays via communication link to enhance the efficiency of protection coordinationand to decrease the operating time of relays. The multi-agent protection scheme proposed in [126] divides the system into various protection zones. This protection scheme has distributed control but makes coordinated decisions. Then, a peer-to-peer multi-agent protection coordination is suggested in [127]. A multi-agent approach is also used in cases where the operational timing of relays is longer due to small fault currents in the network. The inverter based DGs connected to low voltage network contribute small amount of current to the fault points [128], and [129]. Also, a communication based protection coordination scheme using synchro-phasors is used in [130].

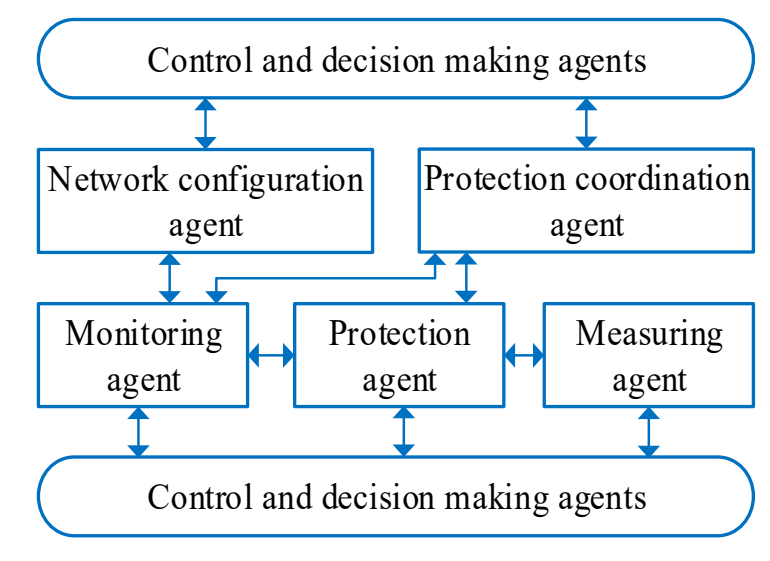

Fig.7. Multi-agent relaying scheme.

TABLE IV

SUMMARY OF METHODS FOR PROTECTION COORDINATION OF DGS

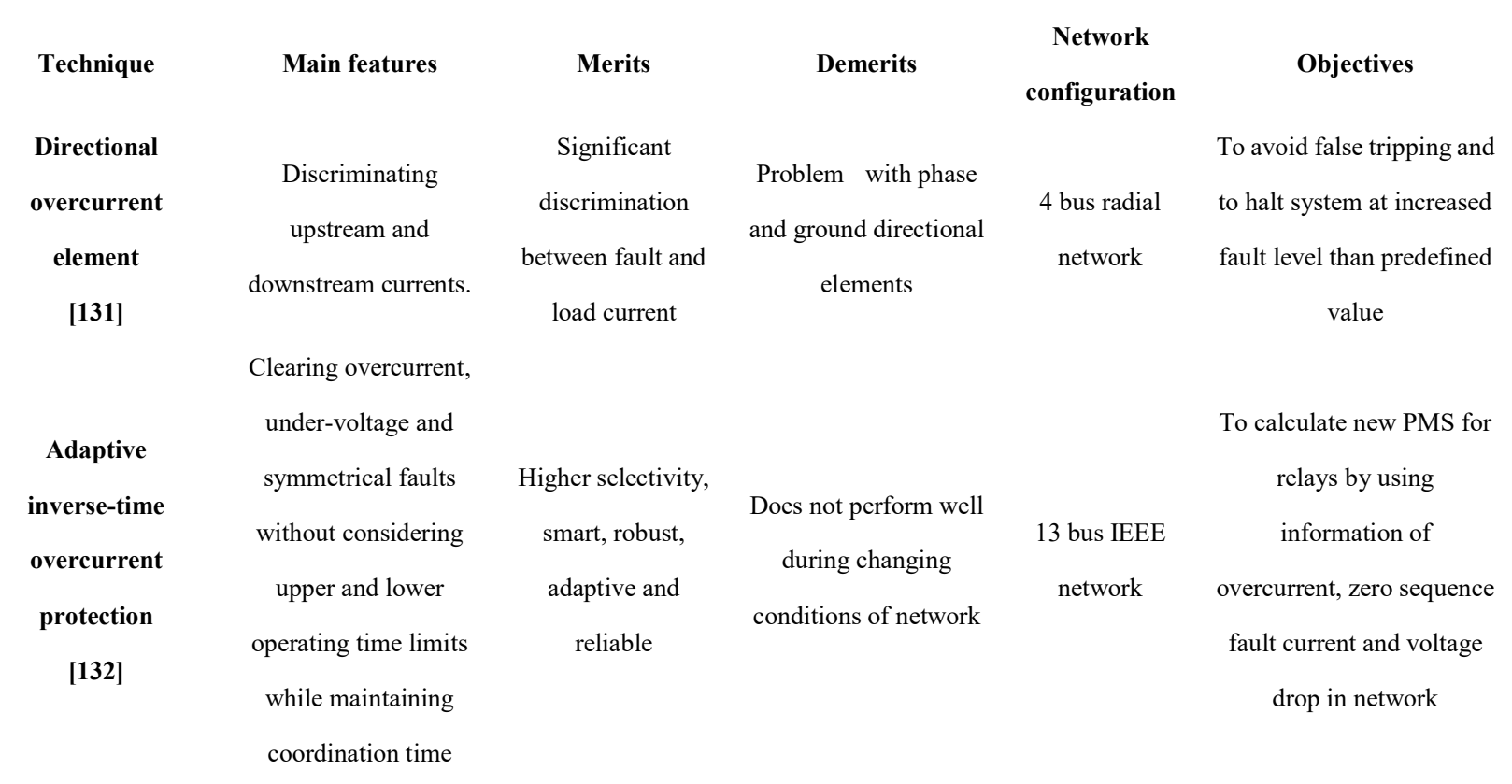




\begin{tabular}{cc} 
& Sizing and placing \\
Optimal location & DGs so that have low \\
and sizing of DG & effect on protection \\
[133], [134], [135], & scheme of network \\
\hline [136] &
\end{tabular}

Achieving most of

Time coordination

method

[137]

\section{Solid state}

unidirectional fault

current limiter

(SSUFCL)

[138]

\begin{tabular}{|c|c|}
\hline \multirow{2}{*}{$\begin{array}{c}\text { Adaptive } \\
\text { differential current }\end{array}$} & fault level and network \\
\hline & configuration are \\
\hline mineremitar curtent & required for relay \\
\hline & coordination in both \\
\hline [IJ) & grid-connected and \\
\hline & islanded mode DGs \\
\hline & Deciding settings of \\
\hline Multi-agent & digital overcurrent \\
\hline laptive protection & relays on the basis of \\
\hline coordination & condition of agents \\
\hline$[140],[141]$ & and communication \\
\hline & between them \\
\hline
\end{tabular}

\section{Directional}

protection with

fault current

limiter (FCL)

[142]
Determining settings

$$
\text { of FCL through }
$$

algorithm that limits

the fault current

Discinnecting DG

from the system when

voltage falls below 0.5
Economical results

in least outage

duration, does not

require network

Not efficient with high

penetration of DGs

modifications
Generates various
possible solutions
(neighbors)

Suitable for DGs

with storage

system and

converter

technology

Applicable to MV

network with

inverter based DG

technology

Cannot be applied to synchronous DGs

discrimination

between upstream and downstream relays

close to DGs

New relay settings are required to be generated each time with new DGs

Ring-fed
distribution
system
7 bus test
system

To optimize the time and current settings of
overcurrent relays and
characteristics of SSUFCL

3 bus radial network

Continuous

Used for complex networks with frequent changing dynamics

communication between overcurrent relay agents, feeder agents and display agents are required

\section{Eliminates}

complexity in

control strategies,

ensures reliability

and safety of

network at the

lowest costs

Can be applied to

both synchronous

and static DGs

RBTS Bus-2

system/15 bus

IEEE system time and energy costs

To achieve zero supply failure rate and interruption frequency

To avoid false fault detection based on differential current with least frequency deviations between supply and load

To determine relays

2 bus radial network / 4 bus radial network algorithm and communicate with its neighboring agents To minimize the cost

30 bus IEEE system function at zero values of FCLs More laborious,

1 bus radial To maintain standard limited to small DGs 


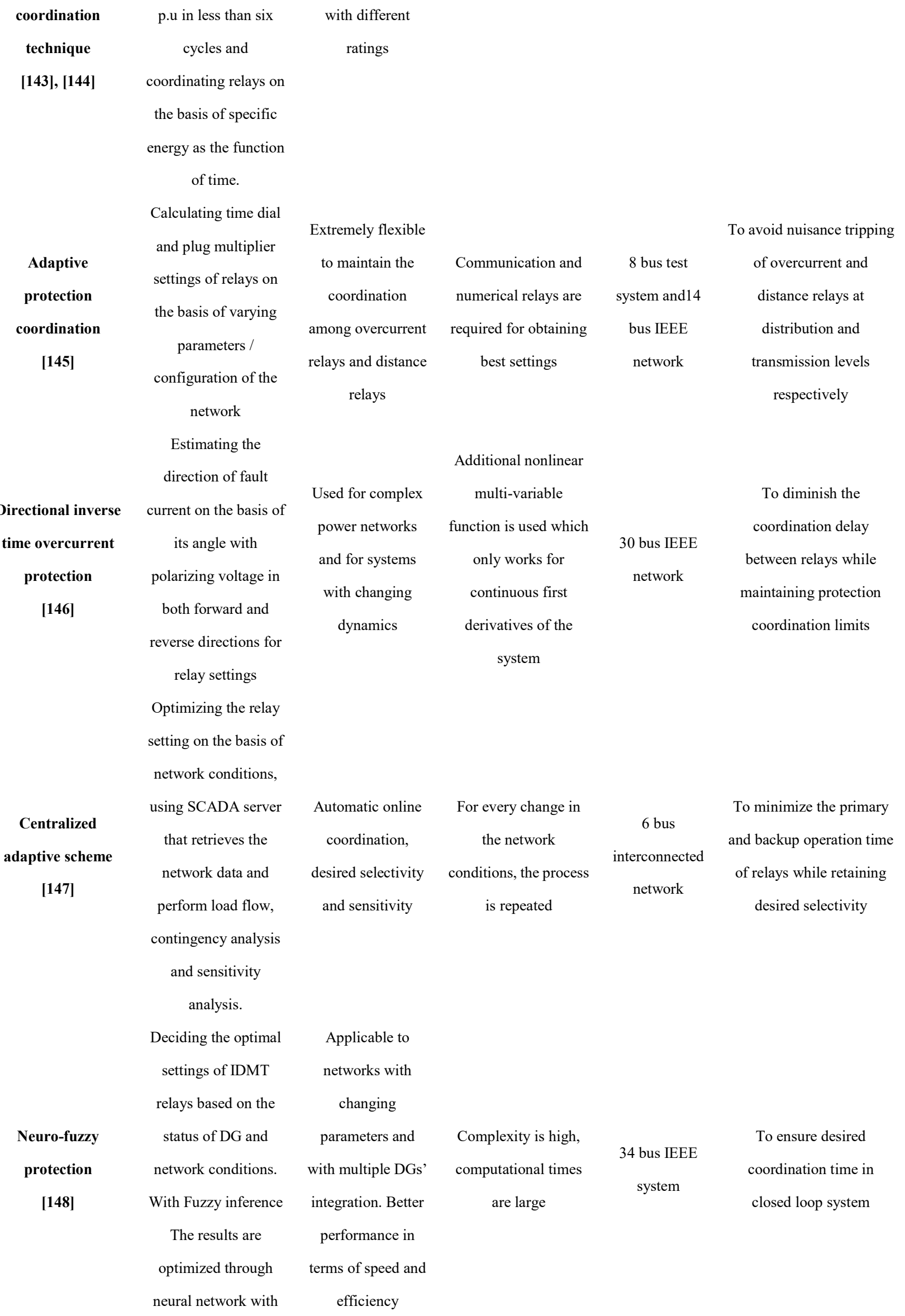


voltage and current

phasor based DFT

algorithm

Using expert system as

Expert System protection

coordination

[90], [149]

Communication
assisted digital
relay scheme

[150]

backup protection

[151]

based on short circuit

decision tool to
investigate the effect
of DG integration and
proposes protection
coordination settings
for relays
Providing

$$
\text { under-voltage and }
$$

overcurrent protection

with grouped relays

capacity of system

Analyzing different

faults based on

coordinated substation

which works on

differential principle

and acts as backup for

master station
Simple, robust and

suitable for system

with multiple

coordination

settings

Used for high

impedance faults

and integration of

multiple DGs

Suitable for

network with

varying power

flows, does not

require complete

information about

system

\section{With changing}

configuration of

network, computation

processing time is

large

Complete knowledge

of entire configuration and parameters of network is difficult and security of

communication link is

$$
\text { necessary. }
$$

\section{Communication}

protocol between

master station and

coordinated station is

14 bus IEEE

system

required to be secure

$22-k V$ test

system

6 and 13 bus

loop network
To identify the maximum and minimum fault currents in the protection

zones

To optimize location and number of relays according to network configuration and characteristics of DGs

To minimize the probability of protection

failure 


\section{Future Scope and Recommendations}

In this article, authors have identified the possible future scope and challenges for protection coordination schemes and DG location and sizing methods.

\section{J. DG location and sizing methods}

1) The optimal sizing and placement of DGs, proper placement of capacitor banks and the network reconfiguration are the three best options for minimizing the power losses in distribution systems. The coordination planning of all these three options results in economical results. Therefore, during the network reconfiguration, proper placement and sizing of DGs, capacitor banks and protection devices should be carried out simultaneously.

2) New model of DG's placement and sizing using information of voltage sag [magnitude+angle] of distribution network with objective of minimizing losses is aim of future research.

3) The optimizations methods used for optimal sizing and location of DGs are based on trial and error methods. In order to improve their performance and efficacy, their objective functions should be evaluated adaptively and automatically.

4) The stability of distribution system should be considered after large penetrations of DGs because the system becomes active then. Moreover, the energy management strategy during transient operation of network should be designed with available distributed generation.

5) The effects of new DG installation on the characteristics of existing DGs in distribution network should be analyzed. The dynamic model for proper placement and sizing of DGs will be an effective solution.

6) With the installation of DGs, not only voltage of network is rised up but also the power quality is significantly being changed. With the online monitoring and control of distribution network, the capacity of network to accommodate new DGs can be determined, the new relay settings can be deduced and the cost of integrating DGs can be calculated. The Online Management System (OMS) integrated with model of DG's placement and sizing is the work of future research.

7) The different parameters of objective functions of DG's placement and sizing algorithms are uncertain such as; output power of distributed sources, future power demand, fuel costs, market trends, charging and discharging characteristics of electric vehicles, future investments, availability of fuel reserves, etc. Therefore, deterministic and evolutionary algorithms should be used to deal with such uncertainties.

K. Schemes of protection coordination

1) High penetration of DGs at distribution levels affects the reach of upstream distance relays at transmission level. Therefore, during installation of multiple DGs, not only relays settings of downstream distribution system but also relays at upstream transmission level should be considered.

2) Since the relays are coordinated while considering the lower limit of CTI and neglecting its upper limit. Thus, in case of low fault current contributions from DGs, the operation of backup overcurrent protection is delayed. Therefore, in order to achieve optimal operation of 
overcurrent relays during such scenarios, time inverse current relay characteristics should be applied in relay coordination schemes.

3) Installation of DGs influences the configuration of distribution network and hence directional relays are installed to distinguish between the upstream and downstream fault currents. In such situations, the selection of relays settings for backup protection becomes more complicated and thus simple curve fitting techniques are ineffective to do so. Therefore, modern communication based techniques are required to solve such issue for highly complex systems.

4) Integration of photo-voltaic systems into power system makes the protection schemes more complicated due to their small fault current contribution. Under such conditions, the accuracy and robustness of protection schemes is a challenging task. Using voltage sag characteristics of system, protection schemes for distribution with PV system can be designed.

5) With high penetration of DGs, the communication based coordination schemes with distributed adaptive techniques become inactive. In future coordination studies, this issue should be considered.

6) In [142], Author used the information of voltage sag for protection coordination of relays and in [145], Author coordinated the relays using fault current angle. Since, with high penetration of DGs into distribution network, not only the magnitude of voltage is affected but also its angle, during the steady state as well as during the transient conditions. Therefore, a new protection scheme can be designed on the basis of both parameters of voltage sag (magnitude+angle), which is ongoing research of Authors

7) Due to interconnection of highly loaded distribution systems and the installations of DGs, the short circuit capacity of network changes adversely and causes sympathetic tripping of relays. Such issue should be considered while integrating DGs into distribution network during steady state and dynamic conditions of system.

\section{Conclusions}

This article presented the detailed review of protection coordination schemes and placement and sizing methods of DGsin distribution networks. The integration of DG into distribution system creates many protection coordination issues. The sensitivity of these issues highly depends upon the place and rating of incoming DG. Therefore, different methods and optimization techniques for optimal placement and sizing of DG were discussed. The most common objective among all the techniques was the reduction of losses and enhancement of voltage profile. The most frequently used methods for proper placement and sizing of DG are Genetic Algorithm (GA) and different practical heuristic algorithms.

After the DGs are optimally sized and placed then issues arise with bidirectional power flows in distribution networks. The existing protection schemes fail to clear the faults correctly. This article addressed various protection coordination methods. The application of different protection schemes were based on the characteristics of network and installed DGs. The protection coordination problems were formulated as linear and non-linear problems and were then evolved by different optimization methods to determine their optimal protection settings. All the discussed protection schemes were based on restraining the adverse effects of DGs and updating their protection characteristics.

This article also discussed possible research gaps, applications and limitations of different protection coordination schemes and DG sizing and placement methods. 


\section{Acknowledgement}

Authors are very much thankful to Wroclaw University of Science and Technology, Poland for providing peaceful environment for conducting this research work. Additionally first author is very much grateful to Prof. Nisar Ahmed Siddiqui, Vice Chancellor Sukkur IBA University for always motivating and appreciating the research work conducted.

\section{REFERENCES}

[1] Howell, S.; Rezgui, Y.; Hippolyte, J.L.; Jayan, B.; Li, H. Towards the next generation of smart grids: Semantic and holonic multi-agent management of distributed energy resources. Renew. Sustain. Energy Rev. 2017, 77, 193-214.

[2] K. Balamurugan, D. Srinivasan, and T. Reindl, "Impact of Distributed Generation on Power Distribution Systems," Energy Procedia, vol. 25, pp. 93-100, Jan. 2012.

[3] Y. Juan, S. Ming, D. Bo, "Research about Impact of DGs in Distribution Network", IEEE Industry Application magazine, pp. 1-6, Sept./oct. 2003.

[4] A. S. O. Ogunjuyigbe, T. R. Ayodele, O. O. Akinola, "Impact of distributed generators on the power loss and voltage profile of subtransmission network", Journal of Electrical Systems and Information Technology, 2015

[5] M.Hlatshwayo, Non-Member, S.Chowdhury, S.P.Chowdhury, and KO.Awodele," Impacts of DO Penetration in the Reliability of Distribution Systems," International Conference on Power System Technology, 2010

[6] M. Mashayekhi, M. Meskin, A. Farahbakhsh, "Impact of Size and Location of Distributed Generation on Overcurrent Relays in Active Distribution Networks", 49th North American Power Symposium (NAPS 2017), pp. 1-7, 2017.

[7] H. M. Sharaf, H.H. Zeineldin, D. K. Ibrahim, E. EL-Din AbouELZahab, "A proposed coordination strategy for meshed distribution systems with DG considering user-defined characteristics of directional inverse time overcurrent relays", Elect. Power and Energy Syst., vol. 65 , pp. 49-58, 2015.

[8] A.R. Haron, A. Mohamed, H. Shareef, "Coordination of Overcurrent Directional and Differential Relays for the Protection of Microgrid System", Procedia Technology, vol. 11, pp. 366-373, 2013.

[9] P. S. Georgilakis, N. D. Hatziargyriou, "Optimal distributed generation placement in power distribution networks: Models methods and future research", IEEE Trans. Power Syst., vol. 28, no. 3, pp. 3420-3428, Aug. 2013.

[10] P. Shanna, A. Tandon, “Techniques for Optimal Placement of DG in Radial Distribution System: A Review”, In Proceeding of the International Conference on Communication, Control and Intelligent Systems, 2015.

[11] W. El-Khattam, M. Salama, "Distributed generation technologies definitions and benefits", Elect. Power Syst. Res., vol. 71, no. 2, pp. 119-128, Oct. 2004

[12] N. S. Rau and Y.-H. Wan, “Optimum location of resources in distributed planning,” IEEE Trans. Power Syst., vol. 9, no. 4, pp. 2014 2020, Nov. 1994.

[13] P. Vovos and J. Bialek, "Direct incorporation of fault level constraints in optimal power flow as a tool for network capacity analysis," IEEE Trans. Power Syst., vol. 20, no. 4, pp. 2125-2134, Nov. 2005.

[14] A. Keane and M. O’Malley, "Optimal allocation of embedded generation on distribution networks," IEEE Trans. Power Syst., vol. 20, no. 3, pp. 1640-1646, Aug. 2005

[15] A. Keane and M. O’Malley, “Optimal utilization of distribution networks for energy harvesting,” IEEE Trans. Power Syst., vol. 22, no. 1, pp. 467-475, Feb. 2007. 
[16] P. N. Vovos, G. P. Harrison, A. R. Wallace, and J. W. Bialek, "Optimal power flow as a tool for fault level-constrained network capacity analysis," IEEE Trans. Power Syst., vol. 20, no. 2, pp. 734-741, May 2005

[17] M. F. AlHajri, M. R. AlRashidi, and M. E. El-Hawary, "Improved sequential quadratic programming approach for optimal distribution generation deployments via stability and sensitivity analyses," Electr. Power Compon. Syst., vol. 38, no. 14, pp. 15951614, Dec. 2010.

[18] F. S. Abu-Mouti, M. E. El-Hawary, "Heuristic curve-fitted technique for distributed generation optimisation in radial distribution feeder systems", IET Gener. Transm. Distrib., vol. 5, no. 2, pp. 172-180, Feb. 2011.

[19] D. Zhu, R. P. Broadwater, K.-S. Tam, R. Seguin, and H. Asgeirsson, "Impact of DG placement on reliability and efficiency with time-varying loads," IEEE Trans. Power Syst., vol. 21, no. 1, pp. 419-427, Feb. 2006

[20] D. Singh, R. K. Mirsa, and D. Singh, "Effect of load models in distributed generation planning," IEEE Trans. Power Syst., vol. 22 , no. 4, pp. 2204-2212, Nov. 2007

[21] S. Kotamarty, S. Khushalani, and N. Schulz, "Impact of distributed generation on distribution contingency analysis," Elect. Power Syst. Res., vol. 78, no. 9, pp. 1537-1545, Sep. 2008

[22] H. Khan and M. A. Choudhry, "Implementation of distributed generation (IDG) algorithm for performance enhancement of distribution feeder under extreme load growth," Int. J. Electr. Power Energy Syst., vol. 32, no. 9, pp. 985-997, Nov. 2010.

[23] L. F. Ochoa, A. Padilha-Feltrin, and G. P. Harrison, "Evaluating distributed time-varying generation through a multiobjective index," IEEE Trans. Power Del., vol. 23, no. 2, pp. 1132-1138, Apr. 2008.

[24] R. A. Jabr and B. C. Pal, "Ordinal optimisation approach for locating and sizing of distributed generation," IET Gener., Transm., Distrib., vol. 3, no. 8, pp. 713-723, Aug. 2009.

[25] N. Khalesi, N. Rezaei, and M.-R. Haghifam, "DG allocation with application of dynamic programming for loss reduction and reliability improvement," Int. J. Electr. Power Energy Syst., vol. 33, no. 2, pp. 288-295, Feb. 2011.

[26] L. F. Ochoa, C. J. Dent, and G. P. Harrison, “Distribution network capacity assessment: Variable DG and active networks," IEEE Trans. Power Syst., vol. 25, no. 1, pp. 87-95, Feb. 2010.

[27] C. J. Dent, L. F. Ochoa, and G. P. Harrison, "Network distributed generation capacity analysis using OPF with voltage step constraints," IEEE Trans. Power Syst., vol. 25, no. 1, pp. 296-304, Feb. 2010

[28] L. F. Ochoa and G. P. Harrison, "Minimizing energy losses: Optimal accommodation and smart operation of renewable distributed generation," IEEE Trans. Power Syst., vol. 26, no. 1, pp. 198 205, Feb. 2011

[29] Y. M. Atwa and E. F. El-Saadany, "Probabilistic approach for optimal allocation of wind-based distributed generation in distribution systems," IET Renew. Power Gener., vol. 5, no. 1, pp. 79-88, Jan. 2011.

[30] G. Harrison and A. Wallace, "Optimal power flow evaluation of distribution network capacity for the connection of distributed generation," Proc. Inst. Electr. Eng.-Gener., Transm., Distrib., vol. 152, no. 1, pp. 115-122, Jan. 2005.

[31] R. S. Al Abri, E. F. El-Saadany, Y. M. Atwa, "Optimal placement and sizing method to improve the voltage stability margin in a distribution system using distributed generation", IEEE Trans. Power Syst., vol. 28, no. 1, pp. 326-334, Feb. 2013

[32] A. Kumar and W. Gao, "Optimal distributed generation location using mixed integer non-linear programming in hybrid electricity markets," IET Gener. Transm. Distrib., vol. 4, no. 2, pp. 281 298, Feb. 2010.

[33] S. Porkar, P. Poure, A. Abbaspour-Tehrani-Fard, and S. Saadate, "Optimal allocation of distributed generation using a two-stage multi-objective mixed-integer-nonlinear programming,” Eur. Trans. Electr. Power, vol. 21, no. 1, pp. 1072 1087, Jan. 2011. 
[34] W. El-Khattam, Y. G. Hegazy, and M. M. A. Salama, "An integrated distributed generation optimization model for distribution system planning," IEEE Trans. Power Syst., vol. 20, no. 2, pp. 1158-1165, May 2005

[35] Singh, D., Mirsa, R.K. and Singh, D, "Effect of Load Models in Distributed Generation Planning", IEEE Trans. Power Syst., Vol. 22, No. 4, pp. 2204-2212, Nov, 2007

[36] H. H. Zeineldin et al., "A protection coordination index for evaluating distributed generation impacts on protection for meshed distribution systems", IEEE Trans. Smart Grid, vol. 4, no. 3, pp. 1523-1532, Sep. 2013.

[37] Kotamarty, S., Khushalani, S. and Schulz, N, "Impact of Distributed Generation on Distribution Contingency Analysis", Elect. Power Syst. Res., Vol. 78, No. 9, pp. 1537-1545, Sep. 2008

[38] SalehK.A.ZeineldinH.H.El-SaadanyE.F.: ' Optimal protection coordination for microgrids considering N-1 contingency', IEEE Trans. Ind. Inf., 2017, 13, (5), pp. 2270-2278

[39] H. L. Willis, "Analytical methods and rules of thumb for modeling DG-distribution interaction," in Proc. IEEE Power Eng. Soc. Summer Meeting, Jul. 2000, pp. 1643-1644.

[40] S.-H. Lee and J.-W. Park, "Selection of optimal location and size of multiple distributed generations by using Kalman filter algorithm," IEEE Trans. Power Syst., vol. 24, no. 3, pp. 1393-1400, Aug. 2009

[41] T. Gözel and M. H. Hocaoglu, "An analytical method for the sizing and siting of distributed generators in radial systems," Elect. Power Syst. Res., vol. 79, no. 6, pp. 912-918, Jun. 2009.

[42] Hung, D.Q., Mithulananthan, N. and Bansal, R.C. (2010), "Analytical Expres-sions for DG Allocation in Primary Distribution Networks", IEEE Trans. Energy Convers., Vol. 25, No. 3, pp. 814-820, Sep.

[43] Hung, D.Q. and Mithulananthan, N. (2013), "Multiple Distributed Generators Placement in Primary Distribution Networks for Loss Reduction", IEEE Trans. Ind Electron., Vol. 60, No. 4, pp. 1700-1708, Apr.

[44] Acharya, N., Mahat, P. and Mithulananthan, N. (2006), "An analytical Approach for DG Allocation in Primary Distribution Network", In!. J Elect. Power Energ Syst., Vol. 28, No. 10, pp. 669-678, Dec.

[45] Costa, P.M. and Matos, M.A. (2009), "Avoided Losses on LV Networksas a Result of Microgeneration", Elect. Power Syst. Res., Vol. 79, No. 4, pp. 629- 634, Apr

[46] K. F. Man, K. S. Tang, and S. Kwong, "Genetic algorithms: Concepts and applications," IEEE Transactions on Industrial Electronics, vol. 43 , no. 5, pp. 519-534, 1996.

[47] C. L. T. Borges and D. M. Falcão, "Optimal distributed generation allocation for reliability, losses, and voltage improvement," Int. J. Elect. Power Energy Syst., vol. 28, no. 6, pp. 413-420, Jul. 2006.

[48] R. K. Singh and S. K. Goswami, "Optimum siting and sizing of distributed generations in radial and networked systems," Elect. Power Compon. Syst., vol. 37, no. 2, pp. 127-145, Jan. 2009.

[49] D. Singh, D. Singh, and K.-S. Verma, "Multiobjective optimization for DG planning with load models," IEEE Trans. Power Syst., vol. 24, no. 1, pp. 427-436, Feb. 2009

[50] R. K. Singh and S. K. Goswami, "Optimum allocation of distributed generations based on nodal pricing for profit, loss reduction, and voltage improvement including voltage rise issue," Int. J. Electr. Power Energy Syst., vol. 32, no. 6, pp. 637-644, Jul. 2010.

[51] G. Caprinelli, G. Celli, F. Pilo, and A. Russo, "Embedded generation planning under uncertainty including power quality issues," Euro. Trans. Electr. Power, vol. 13, no. 6, pp. 381-389, Nov. 2003. 
[52] K.-H. Kim, Y.-J. Lee, S.-B. Rhee, S.-K. Lee, and S.-K. You, "Dispersed generator placement using fuzzy-GA in distribution systems," in Proc. IEEE Power Eng. Soc. Summer Meeting, Jul. 2002, pp. 1148-1153

[53] M. F. Akorede, H. Hizam, I. Aris, and M. Z. A. Ab Kadir, "Effective method for optimal allocation of distributed generation units in meshed electric power systems," IET Gener., Transm., Distrib., vol. 5, no. 2, pp. 276-287, Feb. 2011.

[54] K. Vinothkumar and M. P. Selvan, "Fuzzy embedded genetic algorithm method for distributed generation planning," Electr. Power Compon. Syst., vol. 39, no. 4, pp. 346-366, Feb. 2011

[55] K.-H. Kim, K.-B. Song, S.-K. Joo, Y.-J. Lee, and J.-O. Kim, "Multiobjective distributed generation placement using fuzzy goal programming with genetic algorithm,” Eur. Trans. Electr. Power, vol. 18, no. 3, pp. 217-230, Apr. 2008

[56] J.-H. Teng, Y.-H. Liu, C.-Y. Chen, and C.-F. Chen, "Value-based distributed generator placements for service quality improvements," Int. J. Elect. Power Energy Syst., vol. 29, no. 3, pp. 268-274, Mar. 2007

[57] Prasanna, H.A.M., Kumar, M.V.L., Ananthpadmnabh, T. (2014), "A Novel Approach for Optimal Allocation of a Distributed Generation in a Radial Distribution Feeder for Loss Minimization and Tail End Node Voltage Improvement during Peak Load", IJECES, Vol. 2, No. I, pp. $67-72$

[58] Song, M.-P. and G.-C. Gu. (2004) Research on Particle Swarm Optimization: A Review. Proceedings of the Third International Conference on Machine Learning and Cybernetics, pp. 2216-2241.

[59] W. Prommee and W. Ongsakul, "Optimal multiple distributed generation placement in microgrid system by improved reinitialized socialstructures particle swarm optimization," Euro. Trans. Electr. Power, vol. 21, no. 1, pp. 489-504, Jan. 2011

[60] A. M. El-Zonkoly, "Optimal placement of multi-distributed generation units including different load models using particle swarm optimisation," IET Gener., Transm., Distrib., vol. 5, no. 7, pp. 760 771, Jul.2011

[61] V. R. Pandi, H. H. Zeineldin, W. Xiao, "Determining optimal location and size of distributed generation resources considering harmonic and protection coordination limits", IEEE Trans. Power Syst., vol. 28, no. 2, pp. 1245-1254, May 2013.

[62] AnandNayyar, Rajeshwar Singh, "Ant Colony Optimization- Computational Swarm Intelligence Technique", International Conference on Computing for Sustainable Global Development, pp. 1493-1499, 2016

[63] L. Wang and C. Singh, "Reliability-constrained optimum placement of reclosers and distributed generators in distribution networks using an ant colony system algorithm," IEEE Trans. Syst., Man, Cybern. C, Appl. Rev., vol. 38, no. 6, pp. 757-764, Nov. 2008.

[64] X. Bi and Y. Wang, "An improved artificial bee colony algorithm," in 3rd international conference on computer research and development (ICCRD), vol. 2, 2011, pp. 174-177.

[65] Abu-mouti, F.S. and El-Hawary, M.E. (2009), "Heuristic Curve Fitted Technique for Distributed Generation Optimization in Radial Distribution Feeder System," IET Generation, Transmission and Distribution, Vol. 5, No. 2, pp. 172-180

[66] Suganthan, P.N.: Differential evolution algorithm: recent advances. In: Dediu, A.-H., Martín-Vide, C., Truthe, B. (eds.) TPNC 2012. LNCS, vol. 7505, pp. 30-46. Springer, Heidelberg (2012).

[67] L. D. Arya, A. Koshti, and S. C. Choube, "Distributed generation planning using differential evolution accounting voltage stability consideration," Int. J. Electr. Power Energy Syst., vol. 42, no. 1, pp. 196-207, Nov. 2012.

[68] M. Ammar, S. Bouaziz, Adel M. Alimi and A. Abraham, "Hybrid Harmony Search algorithm for Global Optimization", Fifth World Congress on Nature and Biologically Inspired Computing, pp. 69-75, Fargo-USA, 12-14 August 2013. 
[69] R. Rao, K. Ravindra, K. Satish, S. Narasimham, "Power loss minimization in distribution system using network reconfiguration in the presence of distributed generation", IEEE Trans. Power Syst., vol. 28, no. 1, pp. 317-325, Feb. 2013.

[70] F. Glover (1989) Tabu search—part I. ORSA Journal on Computing, 1(3), 190-206.

[71] K. Nara, Y. Hayashi, K. Ikeda, and T. Ashizawa, “Application of tabu search to optimal placement of distributed generators," in Proc. IEEE Power Eng. Soc. Winter Meeting, Jan. 2001, pp. 918-923

[72] M. E. H. Golshan and S. A. Arefifar, "Optimal allocation of distributed generation and reactive sources considering tap positions of voltage regulators as control variables," Eur. Trans. Electr. Power, vol. 17, no. 3, pp. 219-239, May 2007

[73] Almotaz Y. Abdelaziz, Yasser G. Hegazy, Walid El-khattam, Mahmoud M. Othman: A multi objective optimization for sizing and placement of voltage controlled distributed generation using supervised big bang-big crunch method. Electric Power Components and Systems 43 (2015) 105-117

[74] M. Arikiez, F. Grasso, M. Zito, "Heuristic algorithm for coordinating smart houses in microgrid", 2015 IEEE International Conference on Smart Grid Communications (SmartGridComm), pp. 49-54, Nov 2015.

[75] W. El-Khattam, K. Bhattacharya, Y. Hegazy, and M. M. A. Salama, "Optimal investment planning for distributed generation in a competitive electricity market," IEEE Trans. Power Syst., vol. 19, no. 3, pp. 1674-1684, Aug. 2004

[76] H. Hamedi and M. Gandomkar, "A straightforward approach to minimizing unsupplied energy and power loss through DG placement and evaluating power quality in relation to load variations over time," Int. J. Electr. Power Energy Syst., vol. 35, no. 1, pp. 93-96, Feb. 2012.

[77] B. Banerjee and S. M. Islam, "Reliability based optimum location of distributed generation," Int. J. Electr. Power Energy Syst., vol. 33, no. 8, pp. $1470-1478$, Oct. 2011

[78] S. Ghosh, S. P. Ghoshal, and S. Ghosh, "Optimal sizing and placement of distributed generation in a network system," Int. J. Electr. Power Energy Syst., vol. 32, no. 8, pp. 849-856, Oct. 2010

[79] J. Cavazos, J. E. B. Moss, and M. F. O'Boyle, "Hybrid optimizations: Which optimization algorithm to use?" in Proceedings of the International Conference on Compiler Construction (ETAPS CC'06), ser. LNCS. Vienna, Austria: Springer-Verlag, Mar. 2006, pp. 185-201.

[80] M. Kefayat, A. L. Ara, S. N. Niaki, "A hybrid of ant colony optimization and artificial bee colony algorithm for probabilistic optimal placement and sizing of distributed energy resources", Energy Conversion and Management, vol. 92, pp. 149-161, 2015.

[81] M. Gandomkar, M. Vakilian, and M. Ehsan, "A genetic-based tabu search algorithm for optimal DG allocation in distribution networks," Elect. Power Compon. Syst., vol. 33, no. 12, pp. 1351-1362, Aug. 2005.

[82] M. H. Moradi and M. Abedini, "A combination of genetic algorithm and particle swarm optimization for optimal DG location and sizing in distribution systems," Int. J. Electr. Power Energy Syst., vol. 34, no. 1, pp. 66-74, Jan. 2012.

[83] T. J. Sadeh, M. Bashir, E. Kamyab, "Effect of distributed generation capacity on the coordination of protection system of distribution network", Proc. IEEE, pp. 110-115, Jul. 2010.

[84] J. Kennedy, P. Ciufo, A. Agalgaonkar, "A review of protection systems for distribution networks embedded with renewable generation", Renewable and Sustainable Energy Reviews, vol. 58, pp. 1308-1317, 2016.

[85] M. Singh "Protection coordination in distribution systems with and without distributed energy resources- a review" Protection and control of modern power systems (2017) 2:17, p.p. 1-17 
[86] A.H. Etemadi, M. Fotuhi-Firuzabad, "New considerations in modern protection system quantitative reliability assessment", IEEE Trans. Power Del., vol. 24, no. 4, pp. 2213-2222, Oct. 2010

[87] N. Nimpitiwan, G. T. Heydt, R. Ayyanar, S. Suryanarayanan, "Fault current contribution from synchronous machine and inverter based distributed generators", IEEE Trans. Power Del., vol. 22, no. 1, pp. 634-641, Jan. 2007.

[88] S.-H. Liao, "Expert system methodologies and applications: A decade review from 1995 to 2004", Expert Syst. With Appli., vol. 28, no. 1, pp. 93-103, 2005.

[89] Park DH, Kim HK, Choi IY, Kim JK (2012) A literature review and classification of recommender systems research. Expert SystAppl 39(7):10059-10072

[90] K. Tuitemwong, S. Premrudeepreechacharn, "Expert system for protection coordination of distribution system with distributed generators", Int. J. Elect. Power Energy Syst., vol. 33, no. 3, pp. 466-471, 2011.

[91] H. Hong, C. T. Sun, V. Mesa, S. Ng, "Protective device coordination expert system", IEEE Trans. Power Del., vol. 6, pp. 359-365, 1991.

[92] K. Tuitemwong and S. Premrudeepreechacharn, "Expert System for Protective Devices Coordination in Radial Distribution Network with Small Power Producers," Knowledge Creation Diffusion Utilization, pp. 1159-1164, 2007.

[93] L. L. Lai, "Development of an Expert System for Power System Protection Coordination", Fourth International Conference in Power System Protection, pp. 310-314, 1989-April-11-13.

[94] L. L. Lai, "An expert system used in power system protection", IFAC International Symposium, 1989-August.

[95] Lim Seong-Il Lim, Choi Myeon-Song, and Lee Seung-Jae, "Adaptive protection setting and coordination for power distribution systems," Power Systems Conference, 2006. MEPCON 2006. Eleventh International Middle East, vol.1, pp.129-134.

[96] M. Singh, T. Vishnuvardhan, S. G. Srivani, "Adaptive protection coordination scheme for power networks under penetration of distributed energy resources", IET Generation Transmission Distribution, vol. 10, no. 15, pp. 3919-3929, 112016

[97] A. Girgis and S. Brahma, "Effect of distributed generation on protective device coordination in distribution system," in Power Engineering, 2001. LESCOPE '01. 2001 Large Engineering Systems Conference on, 2001, pp. 115-119

[98] S. M. Brahma and A. A. Girgis, "Microprocessor-based reclosing to coordinate fuse and recloser in a system with high penetration of distributed generation," in Power Engineering Society Winter Meeting, 2002. IEEE, 2002, pp. 453-458 vol.1.

[99] B. Li, C. Li, F. Guo, Y. Xin, "Overcurrent protection coordination in a power distribution network with the active superconductive fault current limiter", IEEE Trans. Appl. Supercond., vol. 24, no. 5, Jun. 2014

[100]H. He et al., "Application of a SFCL for fault ride-through capability enhancement of DG in a microgrid system and relay protection coordination", IEEE Trans. Appl. Supercond., vol. 26, no. 7, Oct. 2016

[101]A. Elmitwally, E. Gouda, S. Eladawy, "Optimal Application of Fault Current Limiters for Assuring Overcurrent Relays Coordination with Distributed Generations” Arbian Journal of Science and Engineering, Vol. 41 (9), p.p. 3381-3397, 2016

[102]Hadzi-Kostova, B. and Z. Styczynski, 2006. Network protection in distribution systems with dispersed generation. Proceedings of the IEEE PES Transmission and Distribution Conference and Exhibition, May 21-24, 2006, Dallas, TX, pp: 321-326.

[103] Oudalov, A. and A. Fidigatti, 2009. Adaptive network protection in microgrids. Int. J. Distrib. Energy Resour., 5: 201-226.

[104]S.T.P Srinivas, K. Shanti Swarup, “Optimal relay coordination and communication based protection for micro-grid” IEEE Region 10 Symposium (TENSYMP), 2017 
[105]Chunguang, Y., P. Zhencun, C. Wei and W. Wei, 2009. The study on fault directional relay in protection system for distribution system under high dg penetration level. Proceedings of the Asia-Pacific Power and Energy Engineering Conference, March 27-31, 2009, IEEE., pp: 1-4.

[106]Zamani, M.A., T.S. Sidhu and A. Yazdani, 2011. A protection strategy and microprocessor-based relay for low-voltage microgrids. IEEE Trans. Power Delivery, 26: 1873-1883

[107]Chen, J., Z.Y. He and W. Jiang, 2011. The overview of protection schemes for distribution systems containing micro-grid. Proceedings of the Asia-Pacific Power and Energy Engineering Conference, March 25-28, 2011, IEEE., pp: 1-4.

[108]Nikkhajoei, H. and R.H. Lasseter, 2006. Microgrid fault protection based on symmetrical and differential current components. Public Interest Energy Research California Energy Commission, California, pp: 1-72

[109]Saleh, K. A., Zeineldin, H. H., Al-Hinai, A., and El-Saadany, E. F. (2015). Optimal Coordination of Directional Overcurrent Relays Using a New Time-Current- Voltage Characteristic. IEEE Transactions on Power Delivery, 30(2), 537-544

[110]Saleh, K. A., Zeineldin, H. H., Al-Hinai, and El-Saanday, E. F. (2015). Dual-setting characteristic for directional overcurrent relays considering multiple fault locations. IET Generation, Transmission and Distribution, 99(12), 1332-1340

[111]Manohar, S., Panigrahi, B. K., and Abhyankar, A. R. (2013). Optimal coordination of Directional Overcurrent Relays Using Teaching Learning-Based Optimization Algorithm. International Journal of Electrical Power and Energy Systems, 5, 33-41

[112]M. Mashayekhi, M. Meskin, A. Farahbakhsh, "Impact of Size and Location of Distributed Generation on Overcurrent Relays in Active Distribution Networks", 49th North American Power Symposium (NAPS 2017), pp. 1-7, 2017.

[113]. A. Sa'ed, S. Favuzza, M. G. Ippolito, F. Massaro, "Investigating the Effect of Distributed Generators on Traditional Protection in Radial Distribution Systems", Proc. 2013 IEEE PowerTech, pp. 1-6.

[114]S.B Walke, N.N Jangle, "Impact of distributed generation on relay coordination" Computing Methodologies and Communication (ICCMC), 2017 International Conference on

[115]Javadian, S. A. M., Haghifam, M.-R., Bathaee, S. M. T., and FotuhiFiroozabad, M. (2013). Adaptive centralized protection scheme for distribution systems with DG using risk analysis for protective devices placement. Electrical Power and Energy Systems, 44, 337-345

[116]N. Rezaei and M. R. Haghifam, "Protection scheme for a distribution system with distributed generation using neural networks," International Journal of Electrical Power and Energy Systems, vol. 30, pp. 235-241, 2008

[117]S. A. M. Javadian, et al., "A fault location and protection scheme for distribution systems in presence of dg using MLP neural networks," in Power and Energy Society General Meeting, 2009. PES '09. IEEE, 2009, pp. 1-8

[118]Chelliah, T. R., Thangaraj, R., Allamsetty, S., and Pant, M. (2014). Coordination of directional over current relay using opposition based chaotic differential evolution algorithm. International Journal of Electrical Power and Energy Systems, 55, 341-350

[119]Rezaei, N., and Mr, H. (2008). Protection scheme for a distribution system with distributed generation using neural networks. International Journal of Electrical Power and Energy Systems, 30(4), 235-241

[120]N. Perera and A. D. Rajapakse, "Agent-based protection scheme for distribution networks with distributed generators," in Power Engineering Society General Meeting, 2006. IEEE, 2006, p. 6 pp 
[121] Wayne Hong, H., Chuen-Tsai, S., Mesa, V. M., and Ng, S. (1991). Protective device coordination expert system. IEEE Transactions on Power Delivery, 26(1), 359-365

[122]Zhu, Y., Shaoqun, S., and Wang, D. (2009). Multiagent-based wide area protection with best-effort adaptive strategy. Electrical Power and Energy Systems, 31, 94-99

[123]Laaksonen, H. J. (2010). Protection principles for future microgrids. IEEE Transactions on Power Electronics, 25(12), 2910-2919

[124]W. Hui, et al., "An Adaptive Multiagent Approach to Protection

Relay Coordination With Distributed Generators in Industrial Power Distribution System," IEEE Transactions on Industry

Applications, vol. 46, pp. 2118-2124, 2010

[125]P. Maiola, J. Rolim, "A Multi-Agent System for protection coordination of radial systems in the presence of distributed generation, " 11th International Conference on Developments in Power Systems Protection, 23-26 April 2012.

[126]Katiraei, F., Iravani, M. R., and Lehn, P. W. (2005). Micro-grid autonomous operation during and subsequent to islanding process. IEEE Transactions on Power Delivery, 20(1), 284-292

[127]Chen, C.-R., Lee, C.-H., and Chang, C.-J. (2013). Optimal Overcurrent relay coordination in power distribution system using a new approach. Electrical Power and Energy Systems, 45, 217-222

[128]Velasco, D., Trujillo, C. L., Garcera, G., and Figueres, E. (2010). Review of anti-islanding techniques in distributed generators. Renewable and Sustainable Energy Reviews, 14, 1608-1614

[129] Javadian, SAM, Haghifam, M-R, and Rezaei, N (2009). A fault location and protection scheme for distribution systems in presence of DG using MLP neural networks. In: 2009 IEEE power engineering society general meeting, (pp. 1-8). Calgary, Alberta, Canada

[130]Katiraei, F., Iravani, M. R., and Lehn, P. W. (2005). Micro-grid autonomous operation during and subsequent to islanding process. IEEE Transactions on

Power Delivery, 20(1), 284-292

[131]C.R Thanga, A. Srikanth, "Coordination of Directional Overcurrent Relays using MATLAB/Simulink and their integration into undergraduate Power System protection courses" Advances in Power System Control, Operation and Management (APSCOM 2015), 10th International Conference on

[132]P. Ekta, D.N. Vishwakarma, S.P. Singh, "A new adaptive inverse-time protection scheme for modern distribution systems with distributed generation" Power and Energy Society Innovative Smart Grid Technologies Conference (ISGT), 2017 IEEE

[133]S. Chaitusaney, A. Yokoyama, "An appropriate distributed generation sizing considering recloser-fuse coordination", Proc. IEEE Power Eng. Soc. Transmission and Distribution Conf. Exhibit., pp. 1-6, 2005.

[134]Ch VSS Sailaja, P. V. N. Prasad, "Determination of optimal distributed generation size for losses protection Co-ordination and reliability Evaluation Using ETAP", Power and Energy Systems: Towards Sustainable Energy (PESTSE) 2016 Biennial International Conference on, pp. 1-6, 2016

[135]S. Chaitusaney, A. Yokoyama, "Impact of Protection Coordination on Sizes of Several Distributed Generation Sources", Proc. 7th International Power Engineering Conference (IPEC), vol. 2, pp. 669-674, Dec. 2005.

[136]M. Singh, B. K. Panigrahi, A. R. Abhyankar, R. Mukherjee, R. Kundu, "Optimal location size and protection coordination of distributed generation in distribution network", 2013 IEEE Symposium on Swarm Intelligence (SIS), pp. 221-227, 2013. 
[137]C. W. So and K. K. Li "Protection relay coordination on ring-fed distribution network with distributed generations". Conference on Computers, Communications, Control and Power Engineering Proceedings. TENCON '02. Volume 3,28-31 Oct. 2002, pp. $1885-1888$

[138]E. E. D. Abbas, E. Saeid, H. Hossein, "Co-optimization of Protection Coordination and Power Quality in Microgrids Using Unidirectional Fault Current Limiters" IEEE Transactions on Smart Grid (Volume: PP, Issue: 99 ) 2017

[139]C. Louw, C. Buque, S. Chowdhury, "Modelling and simulation of an adaptive differential current protection scheme for a solar PV microgrid" $3^{\text {rd }}$ Renewable Power Generation Conference (RPG 2014)

[140]Seong-Il Lim, Choi Myeon-Song, and Lee Seung-Jae, "Adaptive protection setting and coordination for power distribution systems," Power Systems Conference, 2006. MEPCON 2006. Eleventh International Middle East, vol.1, pp.129-134.

[141]H. Wan, K. Li, K. Wong, "An adaptive multiagent approach to protection relay coordination with distributed generators in industrial power distribution system", IEEE Trans. Ind. Appl., vol. 46, no. 5, pp. 2118-2124, Sep./Oct. 2010.

[142]M. Barzegari, A.N. Fard, M.M. Hamidi, A.J. Shahrood, “Optimal coordination of directional overcurrent relays in the presence of distributed generation using FCLs" Energy Conference and Exhibition (EnergyCon), 2010 IEEE International

[143]J. C. Gmez, M. M. Morcos, "Coordination of voltage sag and overcurrent protection in DG systems", IEEE Trans. Power Del., vol. 20, no. 1, pp. 214-218, Jan. 2005.

[144]F.A. Viawan, M. Reza, "The Impact of Synchronous Distributed Generation on Voltage Dip and Overcurrent Protection Coordination", International Conference on Future Power Systems IEEE, 2005

[145]Manish Kumar Singh, Naveen Reddy Parne, "A fast Adaptive Protection Scheme for Distributed Generation Connected Networks with Necessary Relay Coordination", Engineering and Systems (SCES) 2013 Students Conference, pp. 1-5, April 2013.

[146]H. Mohamed Sharaf, H. H. Zeineldin, D. K. Ibrahim, E. El, Din Abo. El Zahab, "Protection coordination of directional overcurrent relays considering fault current direction", 5th IEEE PES Innovative Smart Grid Technologies Europe (ISGT Europe), pp. 12-15, October 2014

[147]M. Y. Shih, A. Conde, Z. M. Leonowicz, L. Martirano, "Mitigating the impact of distributed generation on directional overcurrent relay coordination by adaptive protection scheme", Proc. 16th IEEE Int. Conf. Environ. Elect. Eng., pp. 1-6, Jun. 2016.

[148]D.S. Kumar, D. Srinivasan, TA. Reindl, "Fast and scalable protection scheme for distribution networks with distributed generation", IEEE Transactions on Power Delivery, vol. 31, pp. 67-75, 2016.

[149]Broadwater RP, Thompson JC, Rahman S, Sargent A. An expert system for integrated protection design with configurable distribution circuits. II. IEEE Trans Power Delivery 1994;9(2):1121-8.

[150]E. Sortomme, S.S. Venkata and J. Mitra, 'Microgrid protection using communication-Assisted digital relays, ' IEEE Trans. on Power Del., vol.25, no.4, pp.2789-2796, Oct. 2010

[151]Jinghan He, Lin Liu, Fanfan Ding, Changcheng Li, and Dahai Zhang, "A new coordinated backup protection scheme for distribution network containing distributed generation," Protection and Control of Modern 